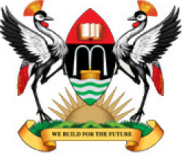

East African School of Higher Education Studies \& Development
Makerere Journal of Higher Education

ISSN: $1816-6822 ; 4(1)(2012) 71-81$

DOI: http://dx.doi.org/10.4314/majohe.v4i1.8

(C) The Author(s) 2012

Reprints \& permission: EASHESD

http://ajol.info/majohe

\title{
How do Organisational Characteristics Relate with Use of Knowledge Management Systems?
}

\author{
Fred Edward K. Bakkabulindi ${ }^{1}$ \\ ${ }^{1}$ East African School of Higher Education Studies and Development [E-mail: \\ fekbakkabulindi@isae.mak.ac.ug]
}

\begin{abstract}
This study sought to establish levels of use of knowledge management systems (KMS) by Masters students in the College of Education and External Studies in Makerere University and to link the same to characteristics related to a given respondent's organisation of employment, namely ability to absorb change, KMS culture, size and leader's KMS change management style. The study involved 60 students who responded to a questionnaire. Data analysis, involving summary statistics and multiple regression, indicated low levels of use of KMS, but none of the four organizational characteristics was a significant correlate of the same. It was thus recommended that stakeholders such as the Makerere University Directorate of ICT Support provide equal treatment such as exposure and/ or training to all of them irrespective of differentials in their organizations of origin.
\end{abstract}

Keywords: Change Management, Knowledge Management Systems, Makerere University

\section{$1 \quad$ Introduction}

Turban, Aronson, Liang \& Sharda (2007) define Knowledge Management (KM) as the systematic and active management of ideas, information, and knowledge residing in an organisation's employees, defining a Knowledge Management System (KMS) as Information and Communication Technology (ICT) that makes KM available throughout an organization. In other words, KMS are ICT tools (e.g. the Internet, Intranets and extranets) that facilitate the creation, storage, transfer and application of organizational knowledge. Turban et al. (2007) observe however that: "encouraging employees to use a KMS, both for contributing knowledge and for seeking knowledge, can be difficult" (p. 487). This observation happens to be true of students in Makerere 
University among whom use of computers and/ or ICT and other KMS tools, has consistently been reported to be low (e.g. Makerere University, 2000; Nassanga, 2001). This failure to make optimal use of KMS by students in the University leads to several undesirable outcomes such as wastage of funds by the University and donors have sank on underutilized or even unutilized facilities (Njiraine, 2000). It is therefore appropriate to isolate the reasons why students in Makerere University are slow to embrace use of KMS. While there could be several contributory factors, theorists on use of innovations (e.g. Kibera, 1997; Rogers, 2003), suggest that organizational characteristics may explain differentials in use of KMS. Hence this study appraising the role of the four organisation characteristics, namely ability to absorb change, KMS culture, size and leader's KMS change management style on use of KMS by Masters students in School of Education in Makerere University.

\section{Review of Related Literature}

\subsection{Organisational Ability to Absorb Change and Use of Innovations}

Organisational ability to absorb change, which can also be termed organizational innovativeness or organisational readiness for change, is the extent to which an organization feels the need for change (Magala, 2001). Mullins (2002) observes that although organizations have to adapt to their environments in order to survive, they tend to feel comfortable operating within the structure, policies and procedures which have been formulated to deal with present situations. They thus set up defences or resistance against change and prefer to concentrate on routine things they perform well. According to Nassejje (2001) resistance may take a number of forms such as persistent reduction in output and the expression that there are a host of reasons why the change will fail. Mullins (2002) attributes the resistance to change to organizational culture, the need to maintain stability, the investment in the status quo, the fear to disrupt past contracts or agreements and the threats to power or influence the proposed change implies. Several authors (e.g. Kizza, 2003; Magala, 2001; Nassejje, 2001) prescribe several measures to curb organizational resistance to change. For example Nassejje (2001) advises that a manager can reduce this resistance by creating dissatisfaction in the organization with the status quo; by reducing the fear of change in the organization; and by encouraging participation of all in the change effort; by trying to compensate those affected by the change.

\subsection{Organisational Culture and Use of Innovations}

Culture, a concept developed from anthropology is difficult to define or explain precisely (Mullins, 2002; Sentamu, 2001). Nevertheless quite a few suggestions 
have come up. It has variously been conceptualized as; "how things are done around here"; as the "underlying assumptions about the way work is performed"; "what is acceptable and not acceptable"; "what behaviour and actions are encouraged and discouraged" (Mullins, 2002: 802). Kizza (2003) observes that if change is to succeed in an organisation, one needs to understand the culture that is to be changed. If the proposed changes contradict cultural biases and traditions, the changes will be difficult to embed in the organisation. Since cultures are difficult to change, organizational culture is among the sources of resistance to change (Kizza, 2003; Rogers, 2003). Kizza (2003) discusses several cultural values that facilitate change in organizations including; (i) a manager adopting a management style that allows for devolution of power from the top to the bottom; (ii) convincing employees that there are benefits in accepting change; (iii) achieving commitment to organizational goals through making employees participate in the change process; (iv) ensuring team work where a leader encourages increased participation, information sharing and collective decision making. He also advocates for (v) valuing each employee's contribution to change; (vi) empowerment of employees to release their creativity, thereby promoting change; (vii) ensuring continuous learning, which will ensure organizational survival as it enhances ability to adapt to the environment.

\subsection{Organisational Size and Use of Innovations}

According to Mullins (2002), organizational size can be defined and measured in different ways, although according to him, the most common indicator of size is the number of persons employed by the organization. Size of an organization may be an important factor in the ability of the organisation to respond to changes in the environment, one of the reasons being that larger organizations have more slack resources set aside to cope with unexpected contingencies (Koberg, 1986; Rogers, 2003). La Rovere (1996) also contends that large firms have clear advantages in use of innovations since they tend to have a smaller rate of indebtedness and hence ability to spend on innovations. He adds that large organisations also have more access to technological information, and thus may be more prone to use of innovations. However, there is an opposing view, which considers large organizations as overly bureaucratic and hence more resistant to use of innovations. In summary, "there is a continuing debate on the comparative advantages of large and small organizations; on whether 'bigger is best' or 'small is beautiful' " (Mullins, 2002: 56) with respect to use of innovations. 


\subsection{Organisational Leader's Change Management Style and Use of Innovations}

Leading change is one of the most important and difficult leadership responsibilities (Yukl, 2002). It is important for managers to understand the reasons for, and nature of, resistance and to adopt a clearly defined strategy for the initiation of change (Mullins, 2002). Rwamukaaga (2001) points out that change management can be subdivided into two approaches, namely planned change and emergency or unplanned change approaches. Planned change is a deliberate pre-meditated move to alter the organisational status. It is change initiated and implemented by change leaders to either solve problems, to adapt to changes or to influence future changes. On the other hand unplanned or emergency change is not a sequential process. It is chaotic and often involves shifting of goals, discontinuation of activities and making of unexpected combinations of changes. For any change process to be successful however, it must be properly managed (Magala, 2001). Mullins (2002) stresses the need for a change manager to use a participatory change style if the change is to succeed, arguing that while in certain situations, it may be necessary to use hierarchical authority to impose change through an autocratic (Theory X) style of leadership, in most cases, change is more effective with a participative (Theory Y) style of leadership, where staff are kept fully informed of proposals, and are encouraged to adopt a positive attitude and have personal involvement in the implementation of change.

\subsection{Hypotheses}

From the literature, the study hypothesized that each of the following four organizational characteristics, namely (i) ability to absorb change, (ii) KMS culture, (iii) size and (iv) leader's KMS change management style, is positively correlated with use of knowledge management systems.

\section{$3 \quad$ Methodology}

Using a quantitative, correlational, survey design, data were collected using a self-administered questionnaire with questions or items on four organisational characteristics, of relevance in this Paper, namely organisational ability to absorb change (four questions: $\alpha=0.688$ ), KMS culture (four questions: $\alpha=$ 0.814 ), size (five questions: $\alpha=0.780$ ) and leader's KMS change management style (four questions: $\alpha=0.843$ ). The questionnaire had 14 questions on use of KMS, conceptualized as use of personal computer applications software (six questions: $\alpha=0.860$ ) and use of Internet applications (eight questions: $\alpha=$ 
0.866). According to Cronbach's Alpha Coefficient Test (Cronbach, 1971), the questionnaire was reliable for the study as all alpha coefficients were above 0.5. Using the said questionnaire, data were collected from a sample of 60 Masters students in the College of Education and External Studies in Makerere University, and analysed using summary statistics (means and standard deviations) and multiple regression.

\section{$4 \quad$ Findings}

\subsection{Background of Respondents}

Of the 60 respondents, the School of Education contributed the majority (53.4\%) while the East African School of Higher Education Studies \& Development (EASHESD) contributed the rest (46.6\%) of the respondents. Ages had a range of 26 years from a minimum of 24 to a maximum of 50 years; arithmetic mean age was 35.1 with a standard deviation of 7.12. Males $(63.3 \%)$ dominated the sample, while regarding income level, most respondents perceived themselves as being of medium income (61\%), followed by $39 \%$ of low income and none $(0.0 \%)$ of high income. Regarding possession of qualification in ICT, the majority $(63.3 \%)$ held none. With respect to current job, the majority (80\%) as expected were teachers (broken as $61.7 \%$ teaching at secondary, $10 \%$ at primary and $8.3 \%$ at tertiary).

\subsection{Use of KMS}

Use of knowledge management systems (KMS) was broken into two sections, namely six questions on use of personal computer (PC) applications software and eight questions on use of Internet facilities, respectively. Each question or item was scaled in such a way that $1=$ Very rarely or never, including never heard of it; $2=$ Rarely use; 3 = Neither rarely nor regularly; $4=$ Regularly; and $5=$ Very regularly. Tables 1 and 2 give respective pertinent summary statistics:

Table 1: Summary statistics on use of PC applications software

\begin{tabular}{lll}
\hline Indicator of use of PC applications software & Mean & Rating \\
\hline Word processing software & 3.32 & Fair \\
Spread sheet software & 2.07 & Poor \\
Database management software & 1.66 & Poor \\
Graphics software & 1.86 & Poor \\
Desktop publishing & 1.46 & Very Poor \\
Statistical or data analysis software & 1.48 & Very Poor \\
Overall & 2.02 & Poor \\
\hline
\end{tabular}


Table 2: Summary statistics on use of Internet facilities

\begin{tabular}{lll}
\hline Indicator of use of Internet facilities & Mean & Rating \\
\hline Email & 3.59 & Good \\
Web surfing & 3.68 & Good \\
Bulletin board, mailing lists, discussion groups & 1.82 & Poor \\
Computer conferencing systems & 1.46 & Very Poor \\
Video conferencing systems & 1.51 & Poor \\
Electronic journals, newsletters & 2.38 & Poor \\
Electronic databases & 1.64 & Poor \\
On-line library catalogues & 2.21 & Poor \\
Overall & 2.31 & Poor \\
\hline
\end{tabular}

According to Table 1, among PC applications software, only word processing recorded a fair level of use. Table 2 suggests that among Internet applications, only e-mail and web surfing tended to be regularly used. An overall average index ("KMS" from the 14 questions or items in Tables 1 and 2) had a mean = 2.17 , which suggested that the majority of respondents were poor users of KMS, that is rare users of the same.

\subsection{Organisational Characteristics}

Organisational characteristics of relevance in the study were organisational ability to absorb change (four questions), KMS culture (four questions), size (five questions) and leader's KMS change management style (four questions). All items or questions were Likert-scaled in such a way that $1=$ Strongly Disagree; 2 = Disagree; 3 = Neither Disagree nor Agree; $4=$ Disagree; and $5=$ Strongly Agree. Table 3 gives pertinent summary statistics. Overall aggregates ("Innov", "Culture", "Size" and "Leader") were computed and found to have means that suggested that Masters students in School of Education, Makerere University rated their respective organisations best in terms ability to absorb change (Mean = 3.54); followed by, in terms of KMS culture (Mean = 3.26); size (Mean $=3.14$ ); and lastly in terms of leaders' KMS change management style $($ Mean $=2.88)$. 
Table 3 Organisational ability to absorb change, KMS culture, Size and Leader's KMS change management style

\begin{tabular}{llll}
\hline Variable & Indicators & Mean & Rating \\
\hline Organisational & Organisation is change-oriented & 3.55 Good \\
ability to absorb & Organisation is innovative & 3.67 Good \\
change & Organisation is progressive & 3.75 Good \\
& Organisation is technologically developed & 3.30 Fair \\
& Overall & 3.54 Good \\
Organisational & Organisation believes in sharing of power on KMS & 3.34 Fair \\
KMS culture & Organisation ensures participations of all in KMS & 3.15 Fair \\
& Organisation acknowledges each individual's contribution & 3.12 Fair \\
& to KMS matters & 3.40 Fair \\
& Organisation ensures continuous learning on KMS & 3.26 Fair \\
Organisational & Overall & 3.48 Fair \\
size & Number of staff & 3.03 Fair \\
& Premises & 3.07 Fair \\
& Income & 3.88 Good \\
& Clients (e.g. students) & 2.35 Poor \\
& Number of KMS facilities & 3.14 Fair \\
Leader's KMS & Organge & Organisational head regularly assesses organisation's KMS & 3.00 Fair \\
management & Organisational head gives feedback for all, on KMS & 2.73 Fair \\
& Organisational head is a use-of-KMS change agent & 3.05 Fair \\
& Organisational head ensures participation of all, in KMS & 2.76 Fair \\
& Overall & 2.88 Fair \\
\hline
\end{tabular}

\subsection{Organisational Characteristics as Correlates of Use of Knowledge Management Systems}

Multiple regression analysis of the average use of KMS index ("KMS" from Tables 1 and 2) on the four organizational characteristics ("Innov", "Culture", "Size" and "Leader" from Table 3), yielded the results in Table 4, suggesting that the four organisational characteristics considered, were collectively not good explanatory variables $(\mathrm{F}=0.712, \mathrm{p}=0.589)$ of use of KMS at the five percent level of significance ( $\mathrm{p}>0.05)$.

Table 4: Regression of use of KMS on organizational characteristics

\begin{tabular}{lll}
\hline Organizational characteristic & Beta, B & Significance level, p \\
\hline Ability to absorb change & -0.059 & 0.752 \\
KMS culture & -0.015 & 0.946 \\
Size & 0.210 & 0.244 \\
Leader's KMS change management style & 0.134 & 0.530 \\
\hline
\end{tabular}


Significances (p) in Table 4 led to rejection of all the four research hypotheses, leading to the inference that none of organizational readiness to change, KMS culture, size and leader's KMS change management style significantly correlated with use of KMS at the five percent level of significance (all $\mathrm{p}>$ $0.05)$.

\section{Discussion}

The study suggested that use of KMS by Masters Students in School of Education, Makerere University was poor, thus corroborating earlier researchers got the same result. For example Nassanga (2001) found that students in the University hardly participated in usage and management of ICT. Now the discussion turns to the respective hypotheses.

\subsection{Organisational Ability to Absorb Change and Use of KMS}

The first hypothesis of the study, namely that organizational ability to absorb change, positively influenced use of KMS, was not supported. This was against several earlier studies (Nassejje, 2001; Rwamukaaga, 2001; Sentamu, 2001) which all found inability to absorb change (i.e. resistance to change) as a factor inhibiting change in different contexts. The finding was anomalous as it put into question the assertion by Mullins (2002) to the effect that although organizations have to adapt to their environments in order to survive, they tend to feel comfortable operating within the structure, policies and procedures which have been formulated to deal with present situations, thus setting up defences or resistance against change and prefer to concentrate on routine things they perform well. Could it be that the conceptualization of organisational ability to absorb change (Table 3) was inadequate? Future researchers should provide an answer to this question.

\subsection{KMS Culture and Use of KMS}

The study set out to test the relevance of good KMS culture in enhancing use of KMS, which hypothesis was not supported by the findings. This finding though consistent with a few past studies (e.g. Korpella, 1996), was at odds with a host of others (e.g. Mugweri, 2000; Sentamu, 2001). The finding was surprising as it put into question the theoretical assertion that organizational culture is among the sources of resistance to change (Kizza, 2003). A possible explanation of the unexpected finding could be inadequacy of conceptualization of unit KMS culture since it is said to be difficult to define (Mullins, 2002; Sentamu, 2001). 
May be the one used in Table 3 is different from that used by several earlier researchers. Future researchers ought to close this conceptual gap.

\subsection{Organisational Size and Use of KMS}

The research result disagreed with the initial hypothesis that organizational size was positively related with use of KMS, which was at par with some past studies (e.g. Kanungo \& Chouthoy, 1996). Otherwise the study was at odds with several other studies (e.g. Fedoromicz \& Gelinas, 1998; Koberg, 1986). The explanation for unit size not being a positive significant correlate of use of KMS by Masters students in School of Education in Makerere University could be that while the School is large and therefore potentially having more slack resources (Koberg, 1986; Rogers, 2003) to buy KMS facilities than smaller faculties and institutes in the University, it is such large organizations that have more people to share these KMS facilities, hence the likelihood of these facilities being few compared to the surging number of staff and students. Another possible explanation could be inadequacy of conceptualization of organisation size given that organizational size can be defined and measured in different ways (Mullins, 2002). May be the one used in Table 3 is different from that used by several earlier researchers. This will be food for thought for future researchers. In the meantime the current finding has strengthened to the contention that "there is a continuing debate about the comparative advantages of large and small organizations; or whether 'bigger is best' or 'small is beautiful" "(Mullins, 2002: 566) in regard to use of KMS. Resolution of whether 'bigger is better' or otherwise as far as innovation adoption is concerned, is calling for further research.

\subsection{Organisational Leader's KMS Change Management Style and Use of KMS}

Inconsistent with the hypothesis, the study established that goodness of unit leaders' KMS change management style never significantly correlated with use of KMS, a finding at variance with such studies as Kanungo \& Chouthoy (1996), Nassejje (2001), and Rwamukaaga (2001), in different contexts. The study thus challenges the assertion that if any change process is to be successful, it must be properly managed or led (Magala, 2001; Mullins, 2002; Nassejje, 2001; Rwamukaaga, 2001), which is surprising. Could the surprising result be due to inadequate conceptualization of unit leader's KMS change management style (Table 3)? Future researchers should provide an answer to this question. 


\section{Conclusion}

None of the four organizational characteristics, namely, ability to absorb change, KMS culture, size and leader's KMS change management style was a significant correlate of use of KMS by Masters students in School of Education, Makerere University, implying that relevant charge agents (e.g. Dean of the School and University's Directorate of ICT Support, DICTS), in their quest to enhance use of KMS by the said students, should provide equal treatment such as exposure and/ or training to all of them irrespective of differentials in their organizations of origin.

\section{References}

Cronbach, L. J. (1971). Test validation. In R. L. Thorndike (Ed.). Educational measurement (pp. 443-597). Washington, DC: American Council on Education.

Kanungo, S. and Chouthoy, M. (1996). IT planning in India: Implications for IT effectiveness. Information Technology for Development, 8 (2), 71-87.

Kibera, F. N. (1997). Critical review of theories of adoption of innovations. Makerere Business Journal, pp.195-204: Summary of papers presented at the $4^{\text {th }}$ Annual International Management Conference on Modernisation of African Economies; Challenges and Strategies, November 24-28, organised by the Makerere University Business School, Kampala.

Kizza, J. (2003). Culture, management styles and management of change in public education institutions: A case of national teachers' colleges in Uganda. Unpublished Masters of Business Administration dissertation, Makerere University, Kampala, Uganda.

Koberg, C. S. (1986). Adaptive organizational behaviour of school organisations: An exploratory study. Educational Evaluation and Policy Studies, 8 (2), 139-146.

Korpella, M. (1996). Traditional culture or political economy? On root causes of organizational obstacles of IT in developing countries. Information Technology for Development, 7 (1), 29-42.

La Rovere, R. L. (1996). IT diffusion in small and medium-sized enterprises: Elements for policy definition. Information Technology for Development, 7 (4), 69-181.

Magala, C. (2001). Management of change in tertiary institutions: Case of Makerere University. Unpublished Masters of Business Administration dissertation, Makerere University, Kampala, Uganda. 
Makerere University. (2000). Strategic plan 2000/01-2004/05. Kampala: Planning and Development Department.

Mugweri, R. A. (2000). Assessment of opportunities and challenges of exploiting ICT networks to improve efficiency and effectiveness in government operations: A case study of Ministry of Finance, Planning and Economic Development. Unpublished Masters of Science (Info Science) dissertation, Makerere University, Kampala, Uganda.

Mullins, L. J. (2002). Management and organizational behaviour. London: Pitman.

Nassanga, M. (2001). Students' participation in ICT usage and management: A case study of East African School of Library and Information Science. Unpublished Bachelors of Library and Information Science dissertation, Makerere University, Kampala, Uganda.

Nassejje, S. (2001). Introduction and management of UEB Clocking System: An organizational development model: A case study of Uganda Electricity Board. Unpublished Masters of Business Administration dissertation, Makerere University, Kampala, Uganda.

Njiraine, D. M. (2000). Under-utilization of internet facilities at universities: A case study of Jomo Kenyatta Memorial Library and United States International University Library. Unpublished Masters of Science (Information Science) dissertation, Makerere University, Kampala, Uganda.

Rogers, E. M. (2003). Diffusion of innovations ( $5^{\text {th }}$ ed.). New York: Free Press.

Rwamukaaga, G. (2001). Management of planned change: A case study of restructuring of Uganda Commercial Bank Limited. Unpublished Masters of Business Administration dissertation, Makerere University, Kampala, Uganda.

Sentamu, F. X. (2001). Information technology, organizational culture and performance of National Water and Sewerage Corporation. Unpublished Master of Business Administration dissertation, Makerere University, Kampala, Uganda.

Turban, E., Aronson, J. E., Liang, T., and Sharda, R. (2007). Decision support and business intelligence systems $\left(8^{\text {th }}\right.$ ed.). New Jersey: Pearson/ PrenticeHall.

Yukl, G. (2002). Leadership in organizations $\left(5^{\text {th }}\right.$ ed.). New Jersey: PrenticeHall. 
